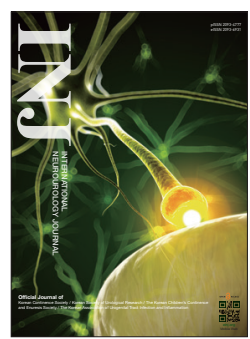

\title{
A Review of Aging and the Lower Urinary Tract: The Future of Urology
}

\author{
Hisae Nishii \\ Department of Urology, National Center for Geriatrics and Gerontology, Obu, Japan
}

Lower urinary tract symptoms (LUTS) are common among elderly people, with significant effects on individuals, caregivers, and the wider health care system. As the elderly population with multiple comorbidities is increasing, the burden of LUTS will increase. This review describes the demographic trends in the aging society, changes in lower urinary tract function with aging, and deterioration of physical and cognitive function in aging, as well as what has been done regarding geriatric urology and what urologists should do to meet the health care needs of the aging population. Frailty and dementia are unmissable factors in the evaluation of elderly patients. Numerous reports have described associations between LUTS and frailty and between LUTS and dementia. Urologists must be aware of the multiplex physical, cognitive, and social characteristics of elderly people. Maintaining a geriatric viewpoint in the diagnosis, treatment, and management of elderly individuals with LUTS will fulfill the unmet needs of elderly people. It is also essential to discuss the treatment and management goals of LUTS with patients and caregivers. Active case identification, appropriate evaluations of LUTS and comorbidities, and a multidisciplinary approach with other health-care professionals are recommended for better treatment and management.

Keywords: Lower urinary tract symptoms; Treatment; Aging; Multidisciplinary

- Conflict of Interest: No potential conflict of interest relevant to this article was reported.

\section{INTRODUCTION}

Lower urinary tract symptoms (LUTS) are common among elderly people and have significant effects on individuals, caregivers, and wider health care system. As the elderly population with multiple comorbidities is increasing, the burden of LUTS will increase. This review describes the demographic trends in aging society, changes in lower urinary tract (LUT) function with aging, and deterioration of physical and cognitive function in aging, as well as what has been done regarding geriatric urology and what urologists should do to meet the health care needs of the aging population.

\section{THE AGING WORLD}

The aging of society is a common phenomenon affecting many developed countries in Europe, North America, and Eastern and Southeastern Asia. The number of older people is growing at the fastest rate in Africa, followed by Latin America, the Caribbean, and Asia; nearly $80 \%$ of the world's older population will reside in less developed countries by 2050 [1]. Thus, the aging issue is inevitable for all countries.

Japan has the longest life expectancy worldwide, which reached 84.6 years in 2019 [2]. The total population of Japan is 126.44 million people as of 2018 . The number of people aged 65 and older is 35.58 million. The percentages of the population

Corresponding author: Hisae Nishii (iD https://orcid.org/0000-0001-7350-710X Department of Urology, National Center for Geriatrics and Gerontology, 7-430 Morioka-Cho, Obu-city, Aichi, 474-8511, Japan

Email: h-nishii@ncgg.go.jp

Submitted: January 24, 2021 / Accepted after revision: August 18, 2021
This is an Open Access article distributed under the terms of the Creative Commons Attribution Non-Commercial License (https://creativecommons.org/licenses/by-nc/4.0/) which permits unrestricted non-commercial use, distribution, and reproduction in any medium, provided the original work is properly cited. 
aged 65 years and older, between 65 and 74 years, and 75 years and older were $28.1 \%, 13.9 \%$, and $14.2 \%$, respectively. By 2065 , 1 in 2.6 people will be 65 years of age and older, and 1 in 3.9 will be 75 years of age and older [3]; these numbers are expected to reach over 30\% in 2025 and 39.9\% in 2060. Through the synergistic impact of the declining birth rate, it is estimated that 1.8 persons in 2025 and 1.2 persons in 2060 will be supporting 1 senior citizen (versus 5.1 persons in 1990 and 2.6 persons in 2010).

The age until which daily life is not hindered (i.e., healthy life expectancy at birth) was 72.14 years for men and 74.79 years for women as of 2016, reflecting an increase compared to 2010 (differences of 1.72 years for men and 1.17 years for women) [3]. This information indicates that a more elderly population with social/physical/cognitive declines and self-care disability will need appropriate treatment and care by health care professionals or their families.

\section{AGING LOWER URINARY TRACT FUNCTION}

Functional changes in the LUT occur both as part of normal aging and in elderly individuals with various diseases. Clinical urodynamic studies have demonstrated that advancing age is associated with a reduced bladder capacity, an increase in uninhibited contractions, decreased urinary flow rate, diminished urethral pressure profile, and increased postvoid residual urine volume $[4,5]$. Numerous in vivo and in vitro studies have investigated the effects of aging on bladder function in rodent models. Increased voiding frequency in mice, rats, and rats with chronic bladder ischemia was observed in in vivo metabolism cage studies [6-10]. Cystometry revealed that voiding frequency increased with age in awake male rats, but decreased in anesthetized female mice [11]. Multiple studies reported increases in bladder capacity and post-residual voiding volume, the pressure threshold for voiding, and baseline intravesical pressure $[12,13]$.

Muscle bath studies showed that potassium chloride-induced depolarization of detrusor strips was similar or greater in old versus young rats in bladder body, whereas calcium-induced depolarization produced lower tension in old rats $[14,15]$. Studies have investigated the detrusor responses to various stimuli. Larger contractions in the bladder base of old versus young rats in response to acetylcholine were reported [16]. However, carbachol-induced contraction in the bladder base was the same in both old and young rats [14]. Inconsistent reports have been published on contraction in the bladder body in old versus young rats, describing larger, similar, and lesser contractions $[13,17]$. The norepinephrine-induced contractile response was the same in the bladder base, but greater in the bladder body in old versus young rats [18]. The relaxant effect of a beta-adrenergic agent on precontracted rat bladder dome strips decreased with increasing age [19]. These findings show an aging-related reduction in bladder compliance and an increase in detrusor instability.

LUTS are more prevalent among the elderly population [2022]. The pathophysiology of LUTS in the elderly population is multifactorial and includes comorbid medical illnesses, neurological and psychiatric conditions, functional impairment, and environmental factors [23-25].

Irwin et al. [26] estimated that $45.2 \%, 10.7 \%, 8.2 \%$, and $21.5 \%$ of the 2008 worldwide population ( 4.3 billion) was affected by at least 1 LUTS, overactive bladder (OAB), urinary incontinence (UI), and LUTS/bladder outlet obstruction (BOO), respectively. Approximately 1.9 billion individuals in the 2008 worldwide population were estimated to experience any LUTS, and the number of affected individuals was projected to increase by $9.3 \%$ ( 2.1 billion) in 2013 and by $18.4 \%$ ( 2.3 billion) in 2018 [26]. An estimated 455 million individuals worldwide experienced $O A B$ in 2008 , with the number of affected individuals anticipated to increase to 500 million (10.0\% increase) and to 546 million by 2018 (20.1\% increase) [26]. Approximately 348 million individuals worldwide in 2008 experienced any UI, and the number of affected individuals was projected to increase by $10.8 \%$ (386 million) in 2013 and by $21.6 \%$ (423 million) in 2018 [26]. An estimated 917 million individuals worldwide experienced LUTS/BOO in 2008, with the number of affected individuals projected to increase by $9.3 \%$ (1.0 billion) in 2013 and by $18.5 \%$ (1.1 billion) in 2018 [26].

Currie et al. [27] revealed that incontinence was associated with a remarkable reduction in health outcomes and health-related quality of life (QoL) outcomes. It is estimated that direct costs are higher among patients with $\mathrm{OAB}$ than among those without $\mathrm{OAB}$, with a 1.4-fold to $>2$-fold increase annually [28]. The high and increasing rate of the population with LUTS poses a health care burden on aging societies, affecting individuals' QoL and resulting in economic consequences such as direct costs for drug therapy, outpatient and inpatient care, pad use, and LUTS-related comorbidities (urinary tract infections, falls and fractures, skin/wound infection) and indirect costs for worker productivity losses (absenteeism and presenteeism) [21, 
22,27-29]

\section{FRAILTY AND LOWER URINARY TRACT SYMPTOMS}

Frequently, the chief complaint of elderly patients does not indicate the specific pathological condition. Elderly people tend to suffer from accumulated impairments of multiple organ systems and commonly present with geriatric syndromes, including falls, cognitive syndromes, delirium, depression, polypharmacy, and UI [30,31].

The development of geriatric syndromes is thought to be multifactorial, involving a declined tolerance capacity against stressors. This status, "vulnerability to poor resolution of homeostasis after a stressor event," is considered as frailty $[32,33]$. There are 2 concepts of frailty: a status encompassing severely disabled to high-risk states and a stage between robustness and disability [34,35].

Two main approaches exist for diagnosing frailty. The phenotype model of Fried et al. [33] measures frailty using the components of the Cardiovascular Health Study criteria. This phenotype describes an age-related decline in physical ability based on (1) unintentional weight loss, (2) self-reported exhaustion, (3) weakness (low grip strength), (4) low physical activity, and (5) slow walking speed. The presence of 3 or more of the aforementioned characteristics indicates frailty, the presence of 1 or 2 indicates prefrailty, and the absence of any indicates robustness [36]. Another approach to diagnosing frailty is the Frailty Index developed by Mitnitski et al. [37], which is used to determine the proportion of accumulated deficits in the variables supporting health and independence.

The reported prevalence of frailty varies substantially, from $4.0 \%$ to $59.1 \%$ in community-dwelling older persons, depending on how frailty status is evaluated [38]. Accumulated evidence shows that the prevalence of frailty increases with age and is higher in women, and older people receiving outpatient care or being placed in nursing homes have a higher prevalence of frailty than community-dwelling older people [38-41]. Frailty is associated with numerous negative health issues in older populations such as death, dependency, dementia, institutionalization, falls and fractures, and polypharmacy [42-44].

A cross-sectional study in Italy examined the association between UI and frailty among the elderly population (age range, 65-83 years; mean age, 73 years) and very elderly population (age range, 90-107; mean age, 92 years) [45]. They categorized the elderly population into nonfrail, prefrail, and frail groups and the very elderly population into frail and highly frail groups, based on their activities of daily living (ADL), the MiniMental State Examination score, grip strength, and self-reported health status [45]. In the elderly population, those with UI had 2.3 and 6.6 times higher odds of being categorized into the prefrail and frail groups, respectively, in comparison to those without UI [45]. In the very elderly population, those with UI had 7.8 times higher odds of being categorized into the highly frail group than those without UI [45].

A prospective cohort study from Singapore examined the association between frailty and the onset of incontinence among elderly hospitalized patients [46]. The prevalence of frailty was $50.0 \%$ when defined by the FRAIL scale. Frail individuals were more likely to have a history of UI than nonfrail subjects $(64.8 \%$ vs. $30.5 \%, \mathrm{P}<0.001)[46]$.

Veronese et al. [47] reported that the prevalence of UI was $39.1 \%$ in those with frailty and $19.4 \%$ in those without frailty. A meta-analysis of 5 studies demonstrated that UI was more than twice as likely in frail people than in nonfrail people (odds ratio $[\mathrm{OR}], 2.28$; 95\% confidence interval [CI], 1.35-3.86; $\mathrm{I}^{2}=61 \%$ ) [47].

Jang et al. [48] conducted a cross-sectional study with 492 community-dwelling older men (mean age, 74.2 years) to investigate the association between the frailty phenotype and LUTS. The prevalence of frailty was $7.3 \%, 16.3 \%$, and $43.2 \%$ in respondents with International Prostate Symptom Scores in the mild, moderate, and severe categories, respectively [48].

An American study showed a higher prevalence of phenotypic frailty among older community-dwelling men with moderate or severe LUTS than in those with mild or no LUTS and a positive association between overall LUTS severity, the storage subscore, voiding subscore, and frailty [49].

A previous study examined the association between frailty and $\mathrm{OAB}$ using the Timed Up and Go test (TUGT) [50]. The authors demonstrated that compared to individuals without $\mathrm{OAB}$, those with $\mathrm{OAB}$ were less likely to have fast TUGT times $(41.8 \%$ vs. $60.8 \%)$, and they were more likely to have slow TUGT times (32.3\% vs. $11.0 \%)$. They revealed that a slower TUGT time or frailty (adjusted for age, race, sex, and number of medications) was a statistically significant predictor of $\mathrm{OAB}$, whereas age (adjusted for slow TUGT speed/frailty, race, sex, and number of medications) was not, although they used a single measure to evaluate frailty [50].

The mechanisms of the association between LUTS and frailty 
remain unknown [49]. Frailty could contribute to LUTS by changing physical activities [51,52]. Park et al. [51] examined the association of prolonged sitting time and low physical activity level with the development of LUTS among middle-aged men. The hazard ratios for incident LUTS comparing the active and inactive groups were 0.94 (95\% CI, 0.89-0.99) and 0.93 (95\% CI, 0.87-0.99), respectively ( $\mathrm{P}=0.011)$. The hazard ratios for LUTS comparing $\geq 5 \mathrm{hr} /$ day sitting time versus $<5 \mathrm{hr} /$ day were 1.08 (95\% CI, 1.00-1.24) and 1.15 (95\% CI, 1.06-1.24), respectively $(\mathrm{P}<0.001)$. A cohort study examining communitydwelling women (median age, 71 years) demonstrated that nocturia was associated with a low step count $(\mathrm{P}=0.02)$, a shorter duration of moderate to vigorous physical activity $(\mathrm{P}=0.001)$, and a greater percentage of time spent in sedentary behavior $(\mathrm{P}=0.016)$ [52]. Likewise, frailty could contribute to LUTS by causing comorbidities (sleep disturbances or metabolic syndrome-related factors) $[53,54]$.

LUTS could also contribute to frailty by interfering with ambulation, social connection, and emotional well-being [55]. A nationwide population-based cohort study revealed a bidirectional relationship between anxiety or depression and LUTS [56]. LUTS patients were 2.12 (95\% CI, 1.95-2.30) and 2.03 (95\% CI, 1.76-2.33) times more likely to develop anxiety or depression, respectively, and patients with anxiety or depression were 2.01 (95\% CI, 1.88-2.14) and 2.37 (95\% CI, 2.13-2.65) times more likely to develop LUTS, respectively [56].

It has not been elucidated whether frailty and LUTS are consequences of a shared pathophysiology. A unifying conceptual model by Inouye et al. demonstrated that shared risk (older age, cognitive impairment, functional impairment, and impaired mobility) may lead to all geriatric syndromes (incontinence, falls, pressure ulcers, delirium, functional decline), which may in turn lead to frailty, with feedback mechanisms enhancing the presence of shared risk factors and geriatric syndromes by forming self-sustaining pathways [30]. Common metabolic disorders such as insulin resistance, inflammatory markers, fat mass, and low-density lipoprotein cholesterol are associated with an increased risk or progression of LUTS [54,57]. A shared mechanism may connect LUTS or frailty or both conditions simultaneously.

Thus, it remains unknown whether the associations between frailty and LUTS are due to each other or caused by a shared mechanism, and further research is required.

\section{DEMENTIA AND LOWER URINARY TRACT SYMPTOM}

Dementia is defined as a progressive cognitive disturbance that results in a loss of independent function. Forty-seven million people live with dementia, 7.7 million new cases of dementia are anticipated annually, and the approximated average survival from the onset of dementia until death is 4.6 years [58]. A systematic review of 21 studies showed that the prevalence of dementia in Japan ranged from $2.9 \%$ to $12.5 \%$, and it has been gradually increasing over the past few years [59]. The Japanese government calculated that 4.6 million elderly people aged 65 years or older had dementia in 2012, and it estimated that the number would increase to 7 million in 2025 as the country's postwar baby boomers become older [58].

There are various causes of dementia [60]. Alzheimer disease $\mathrm{AD})$, the most common neurodegenerative disorder, accounts for an estimated $60 \%-80 \%$ of cases of dementia in the elderly population (older than 65 years of age) [60]. Vascular dementia is one of the most common causes of dementia after $\mathrm{AD}$, accounting for about $15 \%$ of cases [61]. Dementia with Lewy bodies (DLB), which shows spontaneous features of parkinsonism, pronounced fluctuation in attention/alertness, visual hallucinations, and autonomic dysfunction, accounts for $4.6 \%$ of cases of dementia in Japan $[60,62,63]$.

A multicenter cross-sectional study conducted in Germany explored the associated risk factors of UI in subjects receiving home care nursing services ( $\mathrm{N}=923$; women, $65.5 \%$; age, $80.4 \pm 11.2$ years) [64]. The prevalence of UI in subjects with dementia was significantly higher than in those without dementia (adjusted OR, 2.59; 95\% CI, 1.46-4.57) [64].

Rait et al. [65] examined the prevalence of cognitive impairment and associated factors in a population aged 75 years and older $(\mathrm{N}=15,041$; women, $61.5 \%)$. The prevalence of cognitive impairment was 18.3\% (95\% CI, 16.0-20.9). After adjusting for age, sex, and other variables, UI was significantly associated with cognitive impairment (OR, 1.3; 95\% CI: 1.0-1.1) [65].

A prospective cohort study of 6,361 community-dwelling women aged 65 years and older reported an association between the onset of UI and associated risk factors [66]. Subjects were assessed every 2 years (baseline: visit 1, 8 years later: visit 4) [66]. The decline in cognitive and physical function between visits 1 and 2 and between visits 1 and 4 was assessed [66]. At visit 4 , subjects were asked about the onset of UI in the past 12 months [66]. The cognitive and physical function of the overall 
cohort worsened between baseline and visit 4 . Fifty percent of the subjects reported some UI in the past 12 months, and approximately $31 \%$ of them reported at least weekly incontinence [66]. Five percent of subjects reported disruptive incontinence, which interfered with their daily activities [66]. No significant association between recent cognitive decline and weekly incontinence was detected in either the age-adjusted or multivariable-adjusted model [66]. However, recent physical function decline in walking speed significantly increased the risk of UI even after adjusting for variables (daily $3 \%$, weekly $22 \%$, monthly $42 \%, \mathrm{P}=0.002$ for the linear trend) [66]. Cognitive decline was associated with disruptive incontinence after adjusting for variables such as the baseline frequency of incontinence and baseline cognitive function [66,67].

Byles et al. [68] presented longitudinal data on the prevalence and incidence of UI in a large cohort of older women (age, 7075 years) over a 9-year follow-up. They reported a strong longitudinal association between UI and dementia (adjusted OR, 2.34; 95\% CI, 1.64-3.34) [68].

A British study investigated the rate of first diagnosis in primary care of UI among people aged 60-89 years with dementia [69]. They extracted data on 54,816 subjects with dementia and age- and sex-stratified subjects without dementia [69]. The rates of the first diagnosis per 1,000 person-years at risk ( $95 \% \mathrm{CI}$ ) for UI in the subjects with dementia were 42.3 (40.9-43.8) in men and $33.5(32.6-34.5)$ in women [69]. In the nondementia group, the rates were 19.8 (19.4-20.3) in men and 18.6 (18.218.9) in women [69]. After adjusting for age, sex, and comorbidities, the rate ratios of UI, comparing those with dementia to those without, were 3.2 (95\% CI, 2.7-3.7) in men and 2.7 (95\% CI, 2.3-3.2) in women [69].

Thus, it could be concluded that the prevalence of UI is significantly higher in the population with dementia than in that without dementia, and dementia is a risk factor for the onset of LUTS, especially UI.

The mechanism of LUTS caused by dementia involves not only dementia or immobility, but also central and peripheral types of somato-autonomic dysfunction [70-72].

Cerebral dysfunction can lead to a loss of the brain's inhibitory influence on the micturition reflex, resulting in involuntary detrusor overactivity (DO) [73]. Patients with vascular dementia present with various aspects of UI depending on the region of brain damage [71]. In $\mathrm{AD}$, lesions in the cholinergic pathway that originate from the $\mathrm{Ch} 4$ cell group of the nucleus basalis of Meynert in the medial frontal lobe result in DO [72]. In DLB, neurodegeneration in the nigrostriatal dopamine system leads to disinhibition of the micturition reflex, resulting in DO [72, 73].

\section{MANAGEMENT}

Accumulated evidence has revealed that LUTS is an unaddressed and serious issue for the aging society, the aging population, those who support the aging society, and those who care for the aging population. There is room for treatment of LUTS in older adults. Active case finding, optimal assessment, and appropriate management for primary care can lead to significant improvements in QoL.

As the elderly population with LUTS may have coexisting disabilities and comorbidities that may or may not respond to treatment, a complete cure (i.e., full continence) is not the only outcome of treatment. It is advisable to discuss the treatment goals with patients and their caregivers. The International Consultation on Incontinence (ICI) reported 4 potential goals of treatment (independent continence, controlled incontinence/ dependent continence, contained incontinence, and incontinence) in frail older men and women with UI and proposed a management algorithm [74]. After active case identification in all frail elderly people, the ICI also recommends starting an assessment of relevant comorbidities, ADL, QoL, and the goals of treatment for patients and caregivers. The essential first step is to identify treatable and potentially reversible conditions and other factors that can cause or contribute to UI. The common treatable and potentially reversible conditions can be summarized by the mnemonic DIPPERS (D, delirium; I, infection; $\mathrm{P}$, pharmaceutical; P, psychological; E, excess of urine output; R, reduced mobility; $S$, stool impaction). Strong consideration is given to the potential of over-treating asymptomatic bacteriuria as an infection because of the potential adverse outcomes of unwarranted antibiotic treatment. For urgency UI, the guidelines recommend lifestyle interventions, behavioral therapies, and thereafter pharmacological treatment. For patients with significant postvoid residual urine volume, they recommend constipation treatment, medication review, alpha-blocker use for men, and catheter drainage. For stress UI, lifestyle interventions and behavioral therapies are recommended [74,75].

\section{Lifestyle Interventions}

Several lifestyle interventions, including dieting, weight loss, dietary modifications, fluid optimization, and constipation man- 
agement have been evaluated in healthier older and younger women, but not in frail individuals [74]. Clinicians and caregivers must consider that some of these interventions may be inappropriate or impractical for the frail older population [76].

\section{Behavioral Interventions}

Behavioral interventions are the mainstay of UI management in the frail elderly population [77,78]. The efficacy and feasibility of an ultrasound-assisted prompted voiding program for the management of UI in hospitalized older adults and nursing home residents have been reported [79-81]. There were statistically significant post-test improvements in absorbent pad use, as $62.5 \%$ of older hospitalized patients decreased their use, $26.3 \%$ no longer required them, and $37 \%$ remained unchanged [81]. In a 12-week study involving 77 nursing home residents, the absorbent pad cost decreased for $51.9 \%$ of participants and the overall costs decreased by $11.8 \%$ [81]. Moreover, the QoL of health care workers based on the subscales of emotional and mental health significantly improved [81].

Many studies have reported the efficacy of pelvic floor muscle training in the community-dwelling elderly population or in elderly nursing home care settings [82-85]. Pelvic floor muscle training is effective for UI in the elderly population with cognitive impairment [86]. After 12 weeks of supervised pelvic floor muscle training, the mean number of UI episodes per 24 hours decreased by 1.6 (from 3.3 to 1.7 ) in the training group and by 0.5 (from 3.4 to 2.9$)$ in the control group $(\mathrm{P}<0.001)$ [86]. The mean number of micturition episodes and total International Consultation on Incontinence Questionnaire-Urinary Incontinence Short Form scores improved to a significantly greater extent in the training group than in the control group $(\mathrm{P}<0.001)$ [86].

\section{Pharmacotherapy}

Normally, first line medical treatment for benign prostate hyperplasia (BPH)-related LUTS includes alpha-adrenoceptor antagonists (alpha-1-blockers), 5-alpha-reductase inhibitors (5ARIs), and phosphodiesterase-5 inhibitors (PDE5Is) [87]. Combination therapies including alpha-1-blockers+5ARIs, alpha-1-blockers+ PDE5Is, alpha-1-blockers+muscarinic receptor antagonists, and alpha-1-blockers+beta-3-adrenergic agonists are clinically useful [87-90].

The main medications for $\mathrm{OAB}$ symptoms and urgency UI include muscarinic receptor antagonists, beta-3-adrenergic agonists, and combination therapy of those drugs [87].
Recently, a system for prescribing appropriate medications for older persons, the Fit fOr The Aged (FORTA) criteria have been published with respect to drugs for LUTS [91]. This guideline assigned appropriateness levels of LUT medications according to the available data. No medication for LUTS was classified as FORTA A (indispensable). Only dutasteride, finasteride and fesoterodine were classified as FORTA B ("beneficial") and other medications are classified as FORTA C ("careful") or FORTA D ("don't").

The main adverse effect (AE) of alpha-1-blockers is orthostatic hypotension and consequent falls, which lead to significant morbidity [92]. Nonselective alpha-1-blockers are classified as FORTA D. In contrast, the super-selective alpha-1Ablocker, silodosin, which showed no clinically relevant or statistically significant differences versus placebo regarding blood pressure, is rated as FORTA C [93]. Tamsulosin shows a favorable safety profile regarding vasodilative AEs ( $4.2 \%$ compared to $6 \%$ in placebo groups) [94].

Campbell et al. [95] evaluated the association between the anticholinergic cognitive burden (ACB) score and both cognitive impairment and health care utilization. All anticholinergic agents used in the treatment of $\mathrm{OAB}$ are categorized as severe $(\mathrm{ACB}$ score 3) [95]. Each 1-point increase in the mean total daily $\mathrm{ACB}$ score was associated with an increased risk of cognitive impairment (OR, 1.13; 95\% CI, 1.004-1.27, P=0.043) [95]. Each 1-point increase in the mean total daily $\mathrm{ACB}$ score increased the likelihood of inpatient admission (OR, 1.11; 95\% CI, 1.02-1.29; $\mathrm{P}=0.014$ ) and number of outpatient visits after adjusting for demographic characteristics, number of chronic conditions, and prior visit history (estimate, 0.382 ; standard error, $0.113 ; \mathrm{P}=$ 0.001) [95].

A beta-3-adrenergic agonist, mirabegron, was found to be well tolerated when prescribed to patients aged over 65 years old (serious AEs, $0.45 \%$ in the placebo group, $0 \%$ in the mirabegron group; cardiac disorders, $1.1 \%$ in the placebo group, $0.88 \%$ in the mirabegron $25 \mathrm{mg}$ group, and 3.2\% in the mirabegron 5.5\% group). There was no statistically significant change in cognitive function from baseline in comparison to placebo [96].

\section{Surgical Treatment}

Transurethral resection of the prostate (TURP) is the gold standard for LUTS/benign prostate obstruction [87]. However, TURP could be intolerable for frail elderly patients, as it has a $12 \%$ transfusion risk and a $4 \%$ rate of Clavien-Dindo classification grade 3 complications [97,98]. 
Holmium laser enucleation of the prostate (HoLEP) and photoselective vaporization of the prostate are also possible treatments [87]. Compared to TURP, HoLEP has shorter catheterization and hospitalization times, reduced blood loss, and fewer blood transfusions; however, it requires a longer operation time [99-102]. Other minimally invasive therapy includes prostatic urethral lift and intra-prostatic injections [87].

The European Association of Urology guideline presents a flowchart for bothersome LUTS refractory to conservative/ medical treatment [87]. For high-risk patients who cannot undergo surgery under anesthesia, prostatic urethral lift is recommended. For high-risk patients who can undergo anesthesia but cannot stop anticoagulation/antiplatelet therapy, laser vaporization is recommended.

The delay of appropriate treatment is linked to $\mathrm{BPH}$-related complications (urinary retention: $23 \%$ in the pre-BPH medical era vs. $55 \%$ in the $\mathrm{BPH}$ medical treatment era; hydronephrosis: $1.3 \%$ in the pre- $\mathrm{BPH}$ medical era vs. $12.5 \%$ in the $\mathrm{BPH}$ medical treatment era) [103].

A lack of treatment and/or inappropriate management of LUTS induces frequent uncontrolled urinary habits, resulting in falls, fractures, and decreased physical activity [104-106]. Patients can lose their willingness to leave the house or travel, social connections, and hobbies, resulting in social isolation, as patients with $\mathrm{OAB}$ symptoms showed significantly greater symptom bother, worse health-related QoL, less work productivity, and higher rates of depression [54,107]. Consequently, inappropriate treatment of LUTS in the elderly population could lead to a vicious cycle of poor geriatric conditions, including frailty and dementia.

\section{GLOBAL EFFORTS}

As the elderly population has coexisting comorbidities and functional impairments that are not treated or managed by only urologists, a multidisciplinary team approach is regarded as important in the management of LUT dysfunction in this population. Several efforts promoting a multidisciplinary approach for the appropriate management of the geriatric population with LUTS are presented below.

The UK government published guidance setting out the government's quality standards for health and social care services for older people. This guidance established an integrated continence service that promotes the identification, assessment, and care of people with incontinence, including help to maintain continence and organizing across primary care and specialist services [108]. The National Health Service delivers information about UI and prostate problems [109]. Charities such as the Bladder and Bowel Community or Age UK provide information and support for patients, caregivers, and healthcare professionals [110].

In Australia, the National Task Force on Incontinence was established to help address incontinence as a major issue in 1986. In 1988, a 5-year grant from Australian government's Department of Community Services enabled the establishment of a national continence secretariat. The Continence Foundation of Australia, which was established in 1989, promotes information, support, and resources for individuals, caregivers, and professionals. They offer information about continence health, management (including continence products, toilet accessibility, and travel tips), and financial assistance. The national continence helpline also offers information for continence health professionals by showing how to prepare for a consultation. It also provides a variety of academic resources including management guidelines and reports. The Australian government has continuously allocated budgetary support to the Continence Foundation of Australia since 1998 [111].

In Japan, the Society of Geriatric Urology was established in 1990 and developed into the Japanese Society of Geriatric Urology (JSGU) in 2004, with the aims of appropriate management of voiding for elderly and disabled populations and appropriate diagnosis and treatment for the elderly population. The JSGU has more than 1,400 members, half of whom are co-medical staff.

The “Toilet Independence Fee”, which was accepted in 2016, was added to the health insurance coverage by the Japanese Ministry of Health, Labour, and Welfare. This encourages appropriate management and care for patients with LUT dysfunction after removal of a urethral catheter to avoid the unnecessary chronic use of indwelling urinary catheters that cause complications. A hospital that charges the Toilet Independence Fee needs to form a multidisciplinary specialized team, including medical doctors, nurses, and therapists (physiotherapists and occupational therapists). Multidisciplinary interventions per week are calculated as $¥ .2,000$ per time under health insurance coverage. This system represents an epochal shift by evaluating individuals' independence in toileting, not only continence versus incontinence.

A free consulting system for elderly individuals with LUTS is operated by the Japanese local government (Kitakyushu), which 
established it in 2007. Professional advisers who have experience with care regarding voiding difficulties and geriatric problems offer free telephone or face-to-face consultations, supervised by urology specialists [112]. Professional advisers collaborate with other health care professionals (including dementia professionals), homemakers, and public services, depending on an individual's condition [112]. In 2018, the city of Nagoya started a free telephone consulting system for citizens' urinary and defecation problems as well.

\section{CONCLUSIONS}

The consideration and evaluation of geriatric factors are essential components in treating and caring for the growing number of elderly patients with LUTS in order to enable the elderly population to achieve healthy aging. As this field is not well studied yet, urologists have to work together with other health care professionals to unravel the complexities regarding LUTS in vulnerable and higher-risk older individuals. Further research and multidisciplinary collaboration are needed to improve the study, treatment, and management of elderly individuals with LUTS.

\section{REFERENCES}

1. World Health Organization. Decade of healthy ageing 2020-2030 [Internet]. Geneva (Switzerland): World Health Organization; c2020 [cited 2021 Jan 18]. Available from: https://www.who.int/ docs/default-source/decade-of-healthy-ageing/full-decade-proposal/decade-proposal-fulldraft-en.pdf?sfvrsn=8ad3385d_6.

2. Our World in Data. Life expectancy [Internet]. Wales (UK): Our World in Data; [cited 2021 Jan 18]. Available from: https://ourworldindata.org/grapher/life-expectancy?time=1770.2019\&count ry=OWID_WRL.

3. Cabinet Office. Cabinet report [Internet]. Tokyo (Japan): Cabinet Office; [cited 2021 Jan 18]. Available from: https://www8.cao. go.jp/kourei/english/annualreport/index-wh.html.

4. Siroky MB. The aging bladder. Rev Urol 2004;6 Suppl 1:S3-7.

5. Kim JW, Kim SJ, Park JM, Na YG, Kim KH. Past, present, and future in the study of neural control of the lower urinary tract. Int Neurourol J 2020;24:191-9.

6. Chang SL, Howard PS, Koo HP, Macarak EJ. Role of type III collagen in bladder filling. Neurourol Urodyn 1998;17:135-45.

7. Chun AL, Wallace LJ, Gerald MC, Wein AJ, Levin RM. Effects of age on urinary bladder function in the male rat. J Urol 1989;141:
170-3.

8. de Barros CA, Lorenzetti F, Ortiz V, Dambros M. Testosterone supplementation's effects on age-related bladder remodeling - experimental study in rats. Aging Male 2013;16:102-7.

9. Latifpour J, Kondo S, O’Hollaren B, Morita T, Weiss RM. Autonomic receptors in urinary tract: sex and age differences. J Pharmacol Exp Ther 1990;253:661-7.

10. Lepor H, Sunaryadi I, Hartanto V, Shapiro E. Quantitative morphometry of the adult human bladder. J Urol 1992;148:414-7.

11. Birder LA, Kullmann AF, Chapple CR. The aging bladder insights from animal models. Asian J Urol 2018;5:135-40.

12. Chun AL, Wallace LJ, Gerald MC, Levin RM, Wein AJ. Effect of age on in vivo urinary bladder function in the rat. J Urol 1988; 139:625-7.

13. de Groat WC. Integrative control of the lower urinary tract: preclinical perspective. Br J Pharmacol 2006;147:S25-40.

14. Longhurst PA, Eika B, Leggett RE, Levin RM. Comparison of urinary bladder function in 6 and 24 month male and female rats. J Urol 1992;148:1615-20.

15. Saito M, Kondo A, Gotoh M, Kato K. Age-related changes in the rat detrusor muscle: the contractile response to inorganic ions. J Urol 1991;146:891-4.

16. Ordway GA, Esbenshade TA, Kolta MG, Gerald MC, Wallace LJ. Effect of age on cholinergic muscarinic responsiveness and receptors in the rat urinary bladder. J Urol 1986;136:492-6.

17. Munro DD, Wendt IR. Contractile and metabolic properties of longitudinal smooth muscle from rat urinary bladder and the effects of aging. J Urol 1993;150:529-36.

18. Ordway GA, Kolta MG, Gerald MC, Wallace LJ. Age-related change in alpha-adrenergic responsiveness of the urinary bladder of the rat is regionally specific. Neuropharmacology 1986;25: 1335-40.

19. Pagala MK, Tetsoti L, Nagpal D, Wise GJ. Aging effects on contractility of longitudinal and circular detrusor and trigone of rat bladder. J Urol 2001;166:721-7.

20. Hunskaar S, Lose G, Sykes D, Voss S. The prevalence of urinary incontinence in women in four European countries. BJU Int 2004; 93:324-30.

21. McGrother CW, Donaldson MM, Shaw C, Matthews RJ, Hayward TA, Dallosso HM, et al. Storage symptoms of the bladder: prevalence, incidence and need for services in the UK. BJU Int 2004;93:763-9.

22. Homma Y, Yamaguchi O, Hayashi K; Neurogenic Bladder Society Committee. Epidemiologic survey of lower urinary tract symptoms in Japan. Urology 2006;68:560-4. 
23. Coyne KS, Wein A, Nicholson S, Kvasz M, Chen CI, Milsom I. Comorbidities and personal burden of urgency urinary incontinence: a systematic review. Int J Clin Pract 2013;67:1015-33.

24. Yoshida M. Perspectives on overactive bladder in the elderly population. World J Urol 2009;27:729-37.

25. Chancellor MB, Bartolone SN, Lamb LE, Ward E, Zwaans BMM, Diokno A. Underactive bladder; review of progress and impact from the international CURE-UAB initiative. Int Neurourol J 2020;24:3-11.

26. Irwin DE, Kopp ZS, Agatep B, Milsom I, Abrams P. Worldwide prevalence estimates of lower urinary tract symptoms, overactive bladder, urinary incontinence and bladder outlet obstruction. BJU Int 2011;108:1132-8.

27. Currie CJ, McEwan P, Poole CD, Odeyemi IA, Datta SN, Morgan CL. The impact of the overactive bladder on health-related utility and quality of life. BJU Int 2006;97:1267-72.

28. Powell LC, Szabo SM, Walker D, Gooch K. The economic burden of overactive bladder in the United States: a systematic literature review. Neurourol Urodyn 2018;37:1241-9.

29. Onukwugha E, Zuckerman IH, McNally D, Coyne KS, Vats V, Mullins CD. The total economic burden of overactive bladder in the United States: a disease-specific approach. Am J Manag Care 2009;15:S90-7.

30. Inouye SK, Studenski S, Tinetti ME, Kuchel GA. Geriatric syndromes: clinical, research, and policy implications of a core geriatric concept. J Am Geriatr Soc 2007;55:780-91.

31. Cho KJ, Kim JC. Management of urinary incontinence with underactive bladder: a review. Int Neurourol J 2020;24:111-7.

32. Clegg A, Young J, Iliffe S, Rikkert MO, Rockwood K. Frailty in elderly people. Lancet 2013;381:752-62.

33. Fried LP, Tangen CM, Walston J, Newman AB, Hirsch C, Gottdiener J, et al. Frailty in older adults: evidence for a phenotype. J Gerontol A Biol Sci Med Sci 2001;56:M146-56.

34. Rockwood K, Song X, MacKnight C, Bergman H, Hogan DB, McDowell I, et al. A global clinical measure of fitness and frailty in elderly people. CMAJ 2005;173:489-95.

35. Abellan van Kan G, Rolland Y, Bergman H, Morley JE, Kritchevsky SB, Vellas B. The I.A.N.A Task Force on frailty assessment of older people in clinical practice. J Nutr Health Aging 2008;12:29-37.

36. Morley JE, Vellas B, van Kan GA, Anker SD, Bauer JM, Bernabei R, et al. Frailty consensus: a call to action. J Am Med Dir Assoc 2013; 14:392-7.

37. Mitnitski AB, Mogilner AJ, Rockwood K. Accumulation of deficits as a proxy measure of aging. ScientificWorldJournal 2001;1:
323-36.

38. Collard RM, Boter H, Schoevers RA, Oude Voshaar RC. Prevalence of frailty in community-dwelling older persons: a systematic review. J Am Geriatr Soc 2012;60:1487-92.

39. Choi J, Ahn A, Kim S, Won CW. Global prevalence of physical frailty by Fried's Criteria in community-dwelling elderly with national population-based surveys. J Am Med Dir Assoc 2015;16: 548-50.

40. Satake S, Shimada H, Yamada M, Kim H, Yoshida H, Gondo Y, et al. Prevalence of frailty among community-dwellers and outpatients in Japan as defined by the Japanese version of the Cardiovascular Health Study criteria. Geriatr Gerontol Int 2017;17:262934.

41. Kojima G. Prevalence of frailty in nursing homes: a systematic review and meta-analysis. J Am Med Dir Assoc 2015;16:940-5.

42. Castro-Rodríguez M, Carnicero JA, Garcia-Garcia FJ, Walter S, Morley JE, Rodríguez-Artalejo F, et al. Frailty as a major factor in the increased risk of death and disability in older people with diabetes. J Am Med Dir Assoc 2016;17:949-55.

43. Lahousse L, Ziere G, Verlinden VJ, Zillikens MC, Uitterlinden AG, Rivadeneira F, et al. Risk of frailty in elderly with COPD: a population-based study. J Gerontol A Biol Sci Med Sci 2016;71: 689-95.

44. Vermeiren S, Vella-Azzopardi R, Beckwée D, Habbig AK, Scafoglieri A, Jansen B, et al. Frailty and the prediction of negative health outcomes: a meta-analysis. J Am Med Dir Assoc 2016;17: 1163.e1-17.

45. Berardelli M, De Rango F, Morelli M, Corsonello A, Mazzei B, Mari V, et al. Urinary incontinence in the elderly and in the oldest old: correlation with frailty and mortality. Rejuvenation Res 2013;16:206-11.

46. Chong E, Chan M, Lim WS, Ding YY. Frailty predicts incident urinary incontinence among hospitalized older adults-a 1-year prospective cohort study. J Am Med Dir Assoc 2018;19:422-7.

47. Veronese N, Soysal P, Stubbs B, Marengoni A, Demurtas J, Maggi $S$, et al. Association between urinary incontinence and frailty: a systematic review and meta-analysis. Eur Geriatr Med 2018;9: $571-8$.

48. Jang IY, Lee CK, Jung HW, Yu SS, Lee YS, Lee E, et al. Urologic symptoms and burden of frailty and geriatric conditions in older men: the Aging Study of PyeongChang Rural Area. Clin Interv Aging 2018;13:297-304.

49. Bauer SR, Scherzer R, Suskind AM, Cawthon P, Ensrud KE, Ricke WA, et al. Co-occurrence of lower urinary tract symptoms and frailty among community-dwelling older men. J Am Geriatr 
Soc 2020;68:2805-13.

50. Suskind AM, Quanstrom K, Zhao S, Bridge M, Walter LC, Neuhaus J, et al. Overactive bladder is strongly associated with frailty in older individuals. Urology 2017;106:26-31.

51. Park HJ, Park CH, Chang Y, Ryu S. Sitting time, physical activity and the risk of lower urinary tract symptoms: a cohort study. BJU Int 2018;122:293-9.

52. Chu CM, Khanijow KD, Schmitz KH, Newman DK, Arya LA, Harvie HS. physical activity patterns and sedentary behavior in older women with urinary incontinence: an accelerometer-based study. Female Pelvic Med Reconstr Surg 2019;25:318-22.

53. Fukunaga A, Kawaguchi T, Funada S, Yoshino T, Tabara Y, Matsuda F, et al. Sleep disturbance worsens lower urinary tract symptoms: the Nagahama study. J Urol 2019;202:354

54. Park JS, Koo KC, Kim HK, Chung BH, Lee KS. Impact of metabolic syndrome-related factors on the development of benign prostatic hyperplasia and lower urinary tract symptoms in Asian population. Medicine (Baltimore) 2019;98:e17635.

55. Coyne KS, Sexton CC, Irwin DE, Kopp ZS, Kelleher CJ, Milsom I. The impact of overactive bladder, incontinence and other lower urinary tract symptoms on quality of life, work productivity, sexuality and emotional well-being in men and women: results from the EPIC study. BJU Int 2008;101:1388-95.

56. Huang CL, Wu MP, Ho CH, Wang JJ. The bidirectional relationship between anxiety, depression, and lower urinary tract symptoms: a nationwide population-based cohort study. J Psychosom Res 2017;100:77-82.

57. Siddiqui NY, Helfand BT, Andreev VP, Kowalski JT, Bradley MS, Lai HH, et al. Biomarkers implicated in lower urinary tract symptoms: systematic review and pathway analyses. J Urol 2019;202: 880-9.

58. Fukawa T. Prevalence of dementia among the elderly population in Japan. Health Prim Car 2018;2:1-6.

59. Okamura H, Ishii S, Ishii T, Eboshida A. Prevalence of dementia in Japan: a systematic review. Dement Geriatr Cogn Disord 2013; 36:111-8.

60. Ljubenkov PA, Geschwind MD. Dementia. Semin Neurol 2016; 36:397-404.

61. O'Brien JT, Thomas A. Vascular dementia. Lancet 2015;386:1698706.

62. Walker Z, Possin KL, Boeve BF, Aarsland D. Lewy body dementias. Lancet 2015;386:1683-97.

63. Ikejima C, Hisanaga A, Meguro K, Yamada T, Ouma S, Kawamuro Y, et al. Multicentre population-based dementia prevalence survey in Japan: a preliminary report. Psychogeriatrics 2012;12:
120-3.

64. Suhr R, Lahmann NA. Urinary incontinence in home care: a representative multicenter study on prevalence, severity, impact on quality of life, and risk factors. Aging Clin Exp Res 2018;30:58994.

65. Rait G, Fletcher A, Smeeth L, Brayne C, Stirling S, Nunes M, et al. Prevalence of cognitive impairment: results from the MRC trial of assessment and management of older people in the community. Age Ageing 2005;34:242-8.

66. Huang AJ, Brown JS, Thom DH, Fink HA, Yaffe K; Study of Osteoporotic Fractures Research Group. Urinary incontinence in older community-dwelling women: the role of cognitive and physical function decline. Obstet Gynecol 2007;109:909-16.

67. Kim YJ, Tae BS, Bae JH. Cognitive function and urologic medications for lower urinary tract symptoms. Int Neurourol J 2020;24: 231-40.

68. Byles J, Millar CJ, Sibbritt DW, Chiarelli P. Living with urinary incontinence: a longitudinal study of older women. Age Ageing 2009;38:333-8; discussion 251.

69. Grant RL, Drennan VM, Rait G, Petersen I, Iliffe S. First diagnosis and management of incontinence in older people with and without dementia in primary care: a cohort study using The Health Improvement Network primary care database. PLoS Med 2013;10:e1001505.

70. Sakakibara R, Ito T, Uchiyama T, Asahina M, Liu Z, Yamamoto T, et al. Lower urinary tract function in dementia of Lewy body type. J Neurol Neurosurg Psychiatry 2005;76:729-32.

71. Averbeck MA, Altaweel W, Manu-Marin A, Madersbacher H. Management of LUTS in patients with dementia and associated disorders. Neurourol Urodyn 2017;36:245-52.

72. Sakakibara R, Uchiyama T, Yamanishi T, Kishi M. Dementia and lower urinary dysfunction: with a reference to anticholinergic use in elderly population. Int J Urol 2008;15:778-88.

73. Lee SH, Cho ST, Na HR, Ko SB, Park MH. Urinary incontinence in patients with Alzheimer's disease: relationship between symptom status and urodynamic diagnoses. Int J Urol 2014;21:683-7.

74. Gibson W, Johnson T, Kirschner-Hermanns R, Kuchel G, Markland $\mathrm{A}$, Orme $\mathrm{S}$, et al. Incontinence in frail elderly persons: report of the 6th International Consultation on Incontinence. Neurourol Urodyn 2020;40:38-54.

75. National Institute for Health and Clinical Excellence (NICE). Urinary incontinence and pelvic organ prolapse in women: management. NICE guideline [NG123] [Internet]. London: NICE; 2019 [cited 2021 Jul 10]. Available from: https://www.nice.org.uk/ guidance/NG123. 
76. Wagg A, Gibson W, Ostaszkiewicz J, Johnson T 3rd, Markland A, Palmer $\mathrm{MH}$, et al. Urinary incontinence in frail elderly persons: report from the 5th International Consultation on Incontinence. Neurourol Urodyn 2015;34:398-406.

77. Balk E, Adam GP, Kimmel H, Rofeberg V, Saeed I, Jeppson P, et al. Nonsurgical treatments for urinary incontinence in women: a systematic review update. Rockville (MD): Agency for Healthcare Research and Quality (US); 2018.

78. Kilpatrick KA, Paton P, Subbarayan S, Stewart C, Abraha I, CruzJentoft AJ, et al. Non-pharmacological, non-surgical interventions for urinary incontinence in older persons: a systematic review of systematic reviews. The SENATOR project ONTOP series. Maturitas 2020;133:42-8.

79. Iwatsubo E, Suzuki M, Igawa Y, Homma Y. Individually tailored ultrasound-assisted prompted voiding for institutionalized older adults with urinary incontinence. Int J Urol 2014;21:1253-7.

80. Suzuki M, Iguchi Y, Igawa Y, Yoshida M, Sanada H, Miyazaki H, et al. Ultrasound-assisted prompted voiding for management of urinary incontinence of nursing home residents: efficacy and feasibility. Int J Urol 2016;23:786-90.

81. Suzuki M, Miyazaki H, Kamei J, Yoshida M, Taniguchi T, Nishimura K, et al. Ultrasound-assisted prompted voiding care for managing urinary incontinence in nursing homes: a randomized clinical trial. Neurourol Urodyn 2019;38:757-63.

82. Schnelle JF, Alessi CA, Simmons SF, Al-Samarrai NR, Beck JC, Ouslander JG. Translating clinical research into practice: a randomized controlled trial of exercise and incontinence care with nursing home residents. J Am Geriatr Soc 2002;50:1476-83.

83. Kim H, Yoshida H, Suzuki T. The effects of multidimensional exercise treatment on community-dwelling elderly Japanese women with stress, urge, and mixed urinary incontinence: a randomized controlled trial. Int J Nurs Stud 2011;48:1165-72.

84. Sherburn M, Bird M, Carey M, Bø K, Galea MP. Incontinence improves in older women after intensive pelvic floor muscle training: an assessor-blinded randomized controlled trial. Neurourol Urodyn 2011;30:317-24.

85. Stenzelius K, Molander U, Odeberg J, Hammarström M, Franzen $\mathrm{K}$, Midlöv $\mathrm{P}$, et al. The effect of conservative treatment of urinary incontinence among older and frail older people: a systematic review. Age Ageing 2015;44:736-44.

86. Lee BA, Kim SJ, Choi DK, Kwon O, Na HR, Cho ST. Effects of pelvic floor muscle exercise on urinary incontinence in elderly women with cognitive impairment. Int Neurourol J 2017;21:295301.

87. EAU guideline. Management of non-neurogenic male LUTS [In- ternet]. Arnhem (The Netherlands): European Association of Urology; [cited 2021 Jul 10]. Available from: https:/uroweb.org/ guideline/treatment-of-non-neurogenic-male-luts/.

88. Roehrborn CG, Siami P, Barkin J, Damião R, Major-Walker K, Nandy I, et al. The effects of combination therapy with dutasteride and tamsulosin on clinical outcomes in men with symptomatic benign prostatic hyperplasia: 4-year results from the CombAT study. Eur Urol 2010;57:123-31.

89. Wang X, Wang X, Li S, Meng Z, Liu T, Zhang X. Comparative effectiveness of oral drug therapies for lower urinary tract symptoms due to benign prostatic hyperplasia: a systematic review and network meta-analysis. PLoS One 2014;9:e107593.

90. Kakizaki H, Lee KS, Yamamoto O, Jong JJ, Katou D, Sumarsono B, et al. Mirabegron add-on therapy to tamsulosin for the treatment of overactive bladder in men with lower urinary tract symptoms: a randomized, placebo-controlled study (MATCH). Eur Urol Focus 2020;6:729-37.

91. Oelke M, Becher K, Castro-Diaz D, Chartier-Kastler E, Kirby M, Wagg A, et al. Appropriateness of oral drugs for long-term treatment of lower urinary tract symptoms in older persons: results of a systematic literature review and international consensus validation process (LUTS-FORTA 2014). Age Ageing 2015;44:745-55.

92. Welk B, McArthur E, Fraser LA, Hayward J, Dixon S, Hwang YJ, et al. The risk of fall and fracture with the initiation of a prostateselective $\alpha$ antagonist: a population based cohort study. BMJ 2015;351:h5398.

93. Chapple CR, Montorsi F, Tammela TL, Wirth M, Koldewijn E, Fernández Fernández E, et al. Silodosin therapy for lower urinary tract symptoms in men with suspected benign prostatic hyperplasia: results of an international, randomized, double-blind, placebo- and active-controlled clinical trial performed in Europe. Eur Urol 2011;59:342-52.

94. Chapple CR, Baert L, Thind P, Höfner K, Khoe GS, Spångberg A. Tamsulosin $0.4 \mathrm{mg}$ once daily: tolerability in older and younger patients with lower urinary tract symptoms suggestive of benign prostatic obstruction (symptomatic BPH). The European Tamsulosin Study Group. Eur Urol 1997;32:462-70.

95. Campbell NL, Perkins AJ, Bradt P, Perk S, Wielage RC, Boustani $\mathrm{MA}$, et al. Association of anticholinergic burden with cognitive impairment and health care utilization among a diverse ambulatory older adult population. Pharmacotherapy 2016;36:1123-31.

96. Wagg A, Staskin D, Engel E, Herschorn S, Kristy RM, Schermer CR. Efficacy, safety, and tolerability of mirabegron in patients aged $\geq 65 y$ r with overactive bladder wet: a phase IV, double-blind, randomised, placebo-controlled study (PILLAR). Eur Urol 
2020;77:211-20.

97. Cornu JN, Ahyai S, Bachmann A, de la Rosette J, Gilling P, Gratzke $\mathrm{C}$, et al. A systematic review and meta-analysis of functional outcomes and complications following transurethral procedures for lower urinary tract symptoms resulting from benign prostatic obstruction: an update. Eur Urol 2015;67:1066-96.

98. De Nunzio C, Lombardo R, Autorino R, Cicione A, Cindolo L, Damiano R, et al. Contemporary monopolar and bipolar transurethral resection of the prostate: prospective assessment of complications using the Clavien system. Int Urol Nephrol 2013;45: 951-9.

99. Tooher R, Sutherland P, Costello A, Gilling P, Rees G, Maddern G. A systematic review of holmium laser prostatectomy for benign prostatic hyperplasia. J Urol 2004;171:1773-81.

100. Yin L, Teng J, Huang CJ, Zhang X, Xu D. Holmium laser enucleation of the prostate versus transurethral resection of the prostate: a systematic review and meta-analysis of randomized controlled trials. J Endourol 2013;27:604-11.

101. Lourenco T, Pickard R, Vale L, Grant A, Fraser C, MacLennan G, et al. Alternative approaches to endoscopic ablation for benign enlargement of the prostate: systematic review of randomised controlled trials. BMJ 2008;337:a449.

102. Rajbabu K, Chandrasekara SK, Barber NJ, Walsh K, Muir GH. Photoselective vaporization of the prostate with the potassium-titanyl-phosphate laser in men with prostates of $>100 \mathrm{~mL}$. BJU Int 2007;100:593-8.

103. Borth CS, Beiko DT, Nickel JC. Impact of medical therapy on transurethral resection of the prostate: a decade of change. Urology 2001;57:1082-5.

104. Noguchi N, Chan L, Cumming RG, Blyth FM, Handelsman DJ, Seibel MJ, et al. Lower urinary tract symptoms and incident falls in community dwelling older men: the concord health and ageing in men project. J Urol 2016;196:1694-9.

105. Kim KS, Nam JW, Choi BY, Moon HS. The association of lower urinary tract symptoms with incidental falls and fear of falling in later life: The Community Health Survey. Neurourol Urodyn 2018;37:775-84.

106. Marshall LM, Lapidus JA, Wiedrick J, Barrett-Connor E, Bauer DC, Orwoll ES, et al. lower urinary tract symptoms and risk of nonspine fractures among older community dwelling U.S. men. J Urol 2016;196:166-72.

107. Suen LKP, Cheng HL, Yeung SKW, Au-Yeung CH, Lee JCY, Ho KKY, et al. Qualitative insights into the experiences of living with moderate-to-severe lower urinary tract symptoms among community-dwelling ageing males. PLoS One 2017;12:e0187085.

108. National Service Framework for Older People [Internet]. London: Department of Health (UK); [cited 2021 Jul 10]. Available from: https://assets.publishing.service.gov.uk/government/uploads/ system/uploads/attachment_data/file/198033/National_Service_ Framework_for_Older_People.pdf.

109. Health A to Z [Internet]. London: National Health Service; [cited 2021 Jul 10]. Available from: https://www.nhs.uk/conditions/.

110. Bladder conditions and symptoms [Internet]. Henley-in-Arden (UK): Bladder and Bowel Community; 2021 [cited 2021 Jul 10]. Available from: https://www.bladderandbowel.org/bladder/bladderconditions-and-symptoms/.

111. Continence Foundation of Australia [Internet]. Surrey Hills (Australia): Continence Foundation of Australia; 2021 [cited 2021 Jul 10]. Available from: https://www.continence.org.au/.

112. Nishii H, Yoshida Y, Nakato K, Kanzaki Y, Hashimoto T, Kubo K, et al. Successful preventive education of lower urinary tract dysfunction and promotion of independence in toileting skills for elderly citizens, a cooperative activity with urologists, physiotherapists, occupational therapists, nursing staffs, care staffs, non-profit organization staffs administered by local city government [abstract 335]. In: ICS 2017; Florence, Italy; 2017 Sep 12-15. Bristol (UK): International Continence Society; 2017. 